\title{
Educación histórica y competencias educativas $^{1}$
}

\section{Educação histórica e competências educacionais}

\section{History education and educational competences}

\author{
Cosme Gómez-Carrasco* \\ Ramón López-Facal ${ }^{* *}$ \\ Belén Castro-Fernández ${ }^{* *}$
}

\begin{abstract}
RESUMEN
Se presentan resultados de un estudio realizado en las universidades españolas de Murcia y Santiago de Compostela, para examinar las percepciones y conocimientos sobre educación histórica de profesorado de primaria en formación. Se han obtenido datos estadísticamente significativos que permiten un diagnóstico sobre la competencia profesional de los futuros docentes de educación primaria. Se justifica la pertinencia de haber utilizado una metodología cuantitativa para un estudio exploratorio. Los resultados apuntan a que la mayoría de los participantes se identifican, formalmente, con un modelo de profesor crítico, que debe utilizar métodos activos de enseñanza y promover valores éticos relacionados con la justicia social. Esta posición formal contrasta a) con sus modelos implícitos, mucho más tradicionales en sus concepciones teóricas y metodológicas; y b) con su
\end{abstract}

1 Esta investigación ha financiación del Plan Nacional de I+D del gobierno de España y FEDER de la UE (EDU2015-65621-C3-1-R y EDU2015-65621-C3-2-R) y del proyecto "Competencias docentes y métodos activos de aprendizaje. Una investigación evaluativa con el profesorado en formación de ciencias sociales" 20638/JLI/18), financiado por la Fundación Séneca. Agencia de Ciencia y Tecnología de la Región de Murcia.

* Universidad de Murcia. Murcia, España. E-mail: cjgomez@um.es. https://orcid.org/00000002-9272-5177.

** Universidade de Santiago de Compostela, España. E-mail: ramon.facal@usc.es. https:// orcid.org/0000-0002-4147-5024. E-mail: belen.castro@usc.es. https://orcid.org/0000-0001-57743962 
selección de contenidos y prácticas para lograr una educación coherente con el modelo formalmente asumido. En las conclusiones se sugiere la necesidad de mejorar la formación de profesores vinculándola más directamente con las prácticas en las aulas de primaria. Se propone reflexionar sobre la práctica desde la práctica, conectándola a la formación teórica, como modelo para formar maestros competentes.

Palabras clave: Educación histórica. Formación de profesores. Percepciones de estudiantes. Modelo docente.

\title{
RESUMO
}

Os resultados de um estudo realizado nas universidades espanholas de Murcia e Santiago de Compostela são apresentados para examinar as percepções e conhecimentos sobre a educação histórica dos professores do ensino primário em formação. Dados estatisticamente significativos foram obtidos para permitir um diagnóstico sobre a competência profissional dos futuros professores do ensino fundamental. A pertinência de ter utilizado uma metodologia quantitativa para um estudo exploratório é justificada. Os resultados sugerem que a maioria dos participantes se identifica, formalmente, comum modelo de professor crítico, que deve utilizar métodos de ensino ativos e promover valores éticos relacionados à justiça social. Essa posição formal contrasta a) com seus modelos implícitos, muito mais tradicionais em suas concepções teóricas e metodológicas; e b) com sua seleção de conteúdos e práticas para alcançar uma educação coerente com o modelo formalmente assumido. As conclusões sugerem a necessidade de melhorar a formação de professores, ligando-a mais diretamente às práticas da sala de aula primária. Propõe-se refletir sobre a prática a partir da prática, conectando-a à formação teórica, como um modelo para formar professores competentes

Palavras-chave: Educação histórica. Formação de professores. Percepções estudantis. Modelo de professor.

\begin{abstract}
Results from a study carried out in the Spanish universities of Murcia and Santiago de Compostela are discussed. The objective is to examine the perceptions and pedagogical content knowledge about history of preservice primary teachers. The study yielded statistically significant results, which allowed a diagnostic about the professional competence of future primary teachers. Quantitative methods have been employed, and their use in an exploratory study is justified. The findings show that a majority of participants identify themselves, formally, with a model of critical teacher,
\end{abstract}


who should use active teaching strategies and promote ethical values related to social justice. This formal stance stands in contrast with a) their implicit teaching models, more traditional in their theoretical and methodological conceptions; and b) with their selection of contents and practices in order to achieve an education coherent with the model formally endorsed. The discussion suggests the need for improvement in teacher's education, establishing direct connections with the practicum in primary classrooms. We propose a teacher education model based on reflection about practice from practice, connected to theory, in order to educate competent primary teachers.

Keywords: Historical education. Teacher training. Students perceptions. Teaching model.

\section{Introducción}

La aparición en el siglo XXI del concepto pedagógico de competencias ha supuesto un nuevo reto en el ámbito educativo. Sin descartar el potencial que puede tener la aplicación de estas competencias para mejorar el proceso de enseñanza-aprendizaje de las diferentes materias curriculares, es necesario un proceso de adaptación a la epistemología disciplinar de cada una de las áreas de conocimiento (Domínguez, 2015). En opinión de López-Facal (2014), para la aplicación de estas competencias hay que superar una interpretación de conectarlas únicamente con la competitividad. Es necesario haber desarrollado destrezas relacionadas con el tratamiento de la información, contextualizar los datos, relacionarlos con acontecimientos anteriores, simultáneos o posteriores, y valorar su fiabilidad y relevancia para nosotros y para los demás desde una perspectiva ética que favorezca la convivencia. Este tipo de destrezas forman parte de los métodos con los que trabajan los historiadores. Incorporar el método histórico a la educación parece ser una buena estrategia para formar a personas competentes (López-Facal, Gómez, Miralles y Prats, 2017).

Para la implementación de este nuevo enfoque es necesario un cambio en las concepciones del profesorado sobre la enseñanza y aprendizaje de la historia en las aulas preuniversitarias. El análisis de los conocimientos de los docentes en formación se considera crucial para orientar los programas de formación inicial del profesorado y mejorar los procesos de enseñanza-aprendizaje (Darling-Hammond, 2005). Existe abundante bibliografía que ha analizado las creencias y percepciones de los docentes en formación para comprender cómo se pueden utilizar estos constructos para mejorar su formación (Fives \& Buehl, 2012; Woolfolk Hoy, Davis, y Pape, 2006). 
Gran parte de los análisis sobre las concepciones del profesorado se han basado en las propuestas de Shulman (1989) sobre los componentes del conocimiento del profesorado. Especialmente cuando se evalúan profesores, los investigadores tienden a distinguir entre conocimiento de contenido (CK), conocimiento pedagógico/didáctico del contenido (PCK) y conocimiento pedagógico general (GPK). El PCK incluye un conocimiento que relaciona la temática concreta de la materia con las finalidades de la enseñanza. Un conocimiento que profundiza en las representaciones sociales que el alumnado tiene de una materia, en cómo comprende esos conocimientos, en los métodos y recurso necesarios para enseñar ese tópico disciplinar, así como en la selección y organización de los contenidos concretos (Bolívar, 2005).

Hay pocas investigaciones que aborden el PCK en educación histórica y otras ciencias sociales con un sólido soporte empírico que permitan la comparación transnacional (Pollock, 2014). Ya en los trabajos de síntesis de Banks y Parker (1990), y Adler (2008) se puso de manifiesto que la mayoría de las investigaciones sobre formación del profesorado en ciencias sociales se habían realizado desde experiencias concretas y poco generalizables. Destacan estudios clásicos como los de Wilson y Wineburg (1993); McDiarmid (1994); Seixas (1998); Fragnoli (2005); y Bain y Mirel (2006). Unos trabajos que permitieron comprobar las concepciones epistemológicas y metodológicas del profesorado en formación. Posteriormente los trabajos de Westhoff y Polman (2008); Korthagen (2010); o Lévesque (2014) han profundizado en la interrelación existente entre las concepciones epistemológicas del profesorado en relación con los conceptos de pensamiento histórico y la finalidad de enseñanza de la historia (Pollock, 2014). A pesar del incremento de estudios todavía no hay investigaciones consolidadas que aborden el PCK desde una perspectiva holística.

En España también se han incrementado los estudios en los últimos años. Las investigaciones cuantitativas realizadas desde la Universidad de Murcia en los docentes en formación en Educación Primaria y Secundaria han permitido definir diferentes perfiles docentes e identificar el porcentaje de futuros profesores con un perfil disonante, dubitativo, sobre el que poder plantear un programa de intervención (Gómez, Miralles y Chapman, 2017; Gómez, Rodríguez y Mirete, 2018). Las investigaciones cualitativas realizadas en la Universidad de Santiago de Compostela, con un enfoque fenomenológico, han permitido diseñar estudios y programas de intervención (Domínguez-Almansa y López-Facal, 2015 y 2017). Consideramos que el análisis de diagnóstico de las percepciones que tiene el profesorado en formación permite establecer las bases para mejorar las competencias docentes en PCK. 


\section{Metodología}

El objetivo principal de este trabajo es detallar los resultados de un estudio basado en las percepciones del profesorado en formación sobre la enseñanza de la historia y las competencias educativas. Se han concretado en analizar sus percepciones sobre:

- la historia como conocimiento académico;

- las competencias históricas y la metodología docente;

- la educación histórica y los problemas sociales para la construcción de identidades.

El diseño ha sido cuantitativo no experimental, tipo encuesta, para dar respuesta a problemas tanto en términos descriptivos como de relación de variables con información recogida de forma sistemática, garantizando el rigor de los datos (Hernández y Maquilón, 2010). Se ha realizado en el Grado de Magisterio en Educación Primaria. Se seleccionaron cuatro grupos de tercer curso en las universidades de Santiago de Compostela (USC) y Murcia (UMU) en setiembre de 2018. La muestra es incidental. Casi un $80 \%$ de los participantes son mujeres, y un porcentaje parecido (81\%) tienen entre 19 y 22 años. Casi el $60 \%$ de los participantes son de la UMU, y algo más del $40 \%$ de la USC.

Los datos utilizados forman parte de un cuestionario con una escala de valoración cerrada tipo Likert (1-5) titulado "Percepción sobre educación histórica y competencias". Consta de tres bloques temáticos. El primero se ha dedicado a las percepciones del profesorado en formación sobre la historia como conocimiento académico y como materia formativa. Se pide que valoren afirmaciones sobre la naturaleza objetiva, subjetiva o crítica del saber histórico en el ámbito escolar. En esta primera parte adaptamos algunos de los ítems propuestos por Van Sledright y Reddy (2014) de su cuestionario BHQ (Beliefs History Questionnaire). Igualmente, en este primer bloque, se les pide que valore los temas históricos que creen más relevantes para enseñar en el aula. El segundo bloque se ha dedicado a sus recuerdos sobre la metodología didáctica utilizada por los docentes de historia, y sus percepciones sobre los métodos, técnicas y recursos que creen más adecuados para la enseñanza de esta materia. Para este bloque se ha tenido en cuenta trabajos como los de Gómez, Rodríguez y Mirete (2018) o Martínez, Souto y Beltrán (2006). El tercer bloque trata de identificar en qué medida los estudiantes identifican (y se identifican con) algunos aspectos, elementos y criterios, relacionados con la construcción de identidades sociales que pueden proporcionar a los estudiantes una orientación ética para la vida, es decir, una conciencia histórica que permita construir narrativas que den sentido a la vida en sociedad (Rüsen, 2016; Schmidt, 2017). Se indaga sobre sus recuerdos 
como estudiantes en las etapas de escolarización obligatoria y se contrasta con sus percepciones y expectativas como futuros docentes.

\section{Resultados}

\section{Bloque 1: La historia como conocimiento académico}

TABLA 1: LA HISTORIA COMO CONOCIMIENTO ACADÉMICO. DATOS ESTADÍSTICOS (MEDIAS Y DESVIACIÓN ESTÁNDAR)

\begin{tabular}{|c|c|c|c|c|c|}
\hline Item & $\mathrm{N}^{\mathrm{o}}$ & Mín. & Máx. & Media & $\begin{array}{l}\text { Desv. } \\
\text { estándar }\end{array}$ \\
\hline $\begin{array}{l}\text { 1.1. La historia, como ciencia social, consiste en el conocimiento } \\
\text { y relato de los hechos del pasado tal y como ocurrieron }\end{array}$ & 155 & 1 & 5 & 3,08 & 1,029 \\
\hline $\begin{array}{l}\text { 1.2. La historia consiste en una investigación crítica y reflexiva } \\
\text { del pasado }\end{array}$ & 155 & 1 & 5 & 3,96 & ,999 \\
\hline $\begin{array}{l}\text { 1.3. Los relatos históricos se fundamentan en una interpretación } \\
\text { subjetiva por parte del historiador. El pasado es lo que el } \\
\text { historiador interpreta }\end{array}$ & 155 & 1 & 5 & 3,21 & 1,097 \\
\hline $\begin{array}{l}\text { 1.4. El desacuerdo entre historiadores sobre un mismo hecho del } \\
\text { pasado siempre se debe a las dificultades de la fuente y a la } \\
\text { falta de pruebas }\end{array}$ & 155 & 1 & 5 & 3,27 & 1,059 \\
\hline $\begin{array}{l}\text { 1.5. Para interpretar bien las fuentes y aprender historia los } \\
\text { estudiantes necesitan tener buenas habilidades de lectura, } \\
\text { memorización y comprensión }\end{array}$ & 155 & 1 & 5 & 3,30 & 1,034 \\
\hline $\begin{array}{l}\text { 1.6. Los contenidos históricos propuestos en los currículos } \\
\text { educativos deben basarse en los principales acontecimientos } \\
\text { relacionados con el origen y consolidación de cada nación }\end{array}$ & 154 & 1 & 5 & 2,66 & ,902 \\
\hline $\begin{array}{l}\text { 1.7. Los métodos del historiador y los contenidos procedimentales } \\
\text { deben tener un papel fundamental en los currículos } \\
\text { educativos }\end{array}$ & 155 & 1 & 5 & 3,85 & ,876 \\
\hline $\begin{array}{l}\text { 1.8. La esencia de nuestra identidad hay que buscar en los hechos } \\
\text { del pasado. La historia debe tener un papel principal en la } \\
\text { creación de identidades sociales, culturales y políticas }\end{array}$ & 155 & 1 & 5 & 3,65 & ,978 \\
\hline $\begin{array}{l}\text { 1.9. La historia debe ser una materia educativa que guíe en } \\
\text { valores morales y cívicos a través de buenos y malos } \\
\text { ejemplos del pasado }\end{array}$ & 155 & 1 & 5 & 3,92 & ,987 \\
\hline $\begin{array}{l}\text { 1.10. La historia debe ayudar a construir a una ciudadanía crítica, } \\
\text { a través de la reflexión y argumentación de los cambios en el } \\
\text { tiempo, y sus implicaciones en nuestra sociedad actual }\end{array}$ & 154 & 3 & 5 & 4,61 &, 586 \\
\hline $\begin{array}{l}\text { 1.11.1. La evolución histórica generalmente lleva un sentido } \\
\text { progresivo (las cosas mejoran con el paso del tiempo) }\end{array}$ & 155 & 1 & 5 & 2,64 & 1,122 \\
\hline $\begin{array}{l}\text { 1.11.2. La evolución histórica generalmente no lleva un sentido } \\
\text { progresivo o regresivo (las cosas ni mejoran ni empeoran con } \\
\text { el paso del tiempo). }\end{array}$ & 155 & 1 & 5 & 2,97 & 1,156 \\
\hline $\begin{array}{l}\text { 1.11.3. La evolución histórica generalmente lleva un sentido } \\
\text { regresivo (las cosas empeoran con el paso del tiempo) }\end{array}$ & 155 & 1 & 5 & 1,92 & ,901 \\
\hline $\begin{array}{l}\text { 1.11.4. En la evolución histórica los procesos generalmente } \\
\text { tienden a repetirse }\end{array}$ & 155 & 1 & 5 & 3,51 & 1,022 \\
\hline
\end{tabular}

(Continua) 
(Conclusión)

\begin{tabular}{|c|c|c|c|c|c|}
\hline $\begin{array}{l}\text { 1.11.5. En la evolución histórica los procesos ocurren sin ningún } \\
\text { sentido }\end{array}$ & 155 & 1 & 5 & 2,74 & 1,026 \\
\hline 1.12.1. Para comprender el presente & 155 & 2 & 5 & 4,55 &, 594 \\
\hline 1.12.2. Para conocer el origen y consolidación de la nación & 155 & 2 & 5 & 4,18 & ,785 \\
\hline 1.12.3. Para educar en valores sociales y cívicos & 154 & 2 & 5 & 4,27 & ,743 \\
\hline $\begin{array}{l}\text { 1.12.4. Para conocer lo métodos de reconstrucción y explicación } \\
\text { de los hechos históricos }\end{array}$ & 154 & 2 & 5 & 4,06 & ,769 \\
\hline $\begin{array}{l}\text { 1.12.5. Para desarrollar competencias educativas en vocabulario, } \\
\text { cronología, etc }\end{array}$ & 155 & 2 & 5 & 4,31 & ,761 \\
\hline 1.13.1. Vida cotidiana de la gente corriente & 155 & 1 & 5 & 3,73 & 1,002 \\
\hline 1.13.2. Principales personalidades de la política y líderes militares & 155 & 1 & 5 & 3,54 & ,927 \\
\hline 1.13.3. Guerras y conflictos bélicos & 155 & 2 & 5 & 4,10 & ,783 \\
\hline $\begin{array}{l}\text { 1.13.4. Principales acontecimientos históricos que permitan } \\
\text { conocer el origen de la nación }\end{array}$ & 155 & 1 & 5 & 4,15 &, 782 \\
\hline 1.13.5. La cultura de nuestro país y de otros cercanos (europeos) & 155 & 1 & 5 & 4,36 &, 720 \\
\hline 1.13.6. La cultura de otros países más lejanos & 155 & 1 & 5 & 4,00 &, 875 \\
\hline $\begin{array}{l}\text { 1.13.7. Temas económicos: desarrollo de la agricultura, el } \\
\text { comercio o la industria }\end{array}$ & 155 & 2 & 5 & 4,25 & ,687 \\
\hline $\begin{array}{l}\text { 1.13.8. La historia, la cultura y el patrimonio de tu localidad y de } \\
\text { tu región }\end{array}$ & 155 & 1 & 5 & 4,43 & ,773 \\
\hline $\begin{array}{l}\text { 1.13.9. Historias de personajes interesantes: aventureros, } \\
\text { inventores, etc. }\end{array}$ & 155 & 2 & 5 & 3,86 & ,936 \\
\hline $\begin{array}{l}\text { 1.13.10. Los grandes procesos de la humanidad (Revolución } \\
\text { neolítica, Revolución industrial, etc.). }\end{array}$ & 155 & 3 & 5 & 4,46 & ,676 \\
\hline $\begin{array}{l}\text { 1.13.11. Historia de temas concretos que puedan motivar al } \\
\text { alumnado: historia de la vivienda, historia de la alimentación, } \\
\text { historia de los transportes... }\end{array}$ & 155 & 1 & 5 & 4,14 &, 876 \\
\hline $\begin{array}{l}\text { 1.13.12. El desarrollo de los derechos humanos, las } \\
\text { reivindicaciones sociales y las luchas por la igualdad }\end{array}$ & 155 & 1 & 5 & 4,60 & ,680 \\
\hline 1.13.13. El desarrollo de la democracia y la participación política & 155 & 2 & 5 & 4,48 &, 678 \\
\hline 1.13.14. Genocidios, dictaduras, y represiones sociales y políticas & 155 & 2 & 5 & 4,19 &, 836 \\
\hline 1.13.15. Temas medioambientales y la explotación del paisaje & 153 & 1 & 5 & 4,27 & ,960 \\
\hline 1.14.1. Los orígenes de la humanidad & 154 & 1 & 5 & 4,13 &, 876 \\
\hline 1.14.2. La Antigüedad (Grecia, Roma, Egipto, Mesopotamia...) & 155 & 2 & 5 & 4,06 & ,927 \\
\hline 1.14.3. La Edad Media & 154 & 2 & 5 & 3,99 &, 836 \\
\hline 1.14.4. La Edad Moderna (1500-1800) & 154 & 1 & 5 & 4,06 &, 861 \\
\hline $\begin{array}{l}\text { 1.14.5. La Edad Contemporánea hasta el fin de la II Guerra } \\
\text { Mundial }\end{array}$ & 155 & 2 & 5 & 4,46 &, 627 \\
\hline $\begin{array}{l}\text { 1.14.6. El mundo actual (desde el fin de la II Guerra Mundial } \\
\text { hasta la actualidad) }\end{array}$ & 155 & 1 & 5 & 4,59 & ,643 \\
\hline
\end{tabular}

Fuente: Elaboración propia 
En la primera parte, concepciones epistemológicas de la historia como materia escolar, la puntuación más alta la recibe el ítem de que la historia debe ayudar a construir una ciudadanía crítica $(4,61)$. Los ítems que afirman que la historia es una investigación crítica del pasado o que es necesario la introducción del método del historiador en el aula reciben una puntuación media algo más baja (3,96 y 3,85 respectivamente). Aunque existen disparidades entre universidades. La afirmación de que hay que introducir el método del historiador en el aula recibe puntuaciones entre 4 y 5 en el alumnado de la UMU, y entre 3 y 4 en el alumnado de la USC (Gráfico 1). Una explicación a esta disparidad es que los participantes de la UMU ya han cursado dos asignaturas del área de Didáctica de las Ciencias Sociales en el momento de responder al cuestionario, mientras que los participantes de la USC sólo han cursado una asignatura que no incluye contenidos de educación histórica.

GRÁFICO 1. RESULTADOS DESAGREGADOS POR UNIVERSIDADES DEL ÍTEM 1.7: LOS MÉTODOS DEL HISTORIADOR Y LOS CONTENIDOS PROCEDIMENTALES DEBEN TENER UN PAPEL FUNDAMENTAL EN LOS CURRÍCULOS EDUCATIVOS

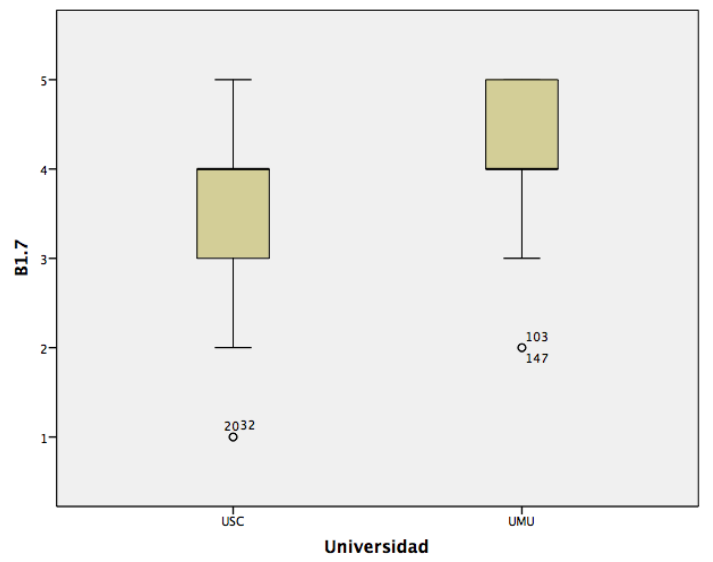

Fuente: Elaboración propia 
GRÁFICO 2. RESULTADOS DESAGREGADOS POR UNIVERSIDADES DEL ÍTEM 1.11.4: EN LA EVOLUCIÓN HISTÓRICA LOS PROCESOS GENERALMENTE TIENDEN A REPETIRSE

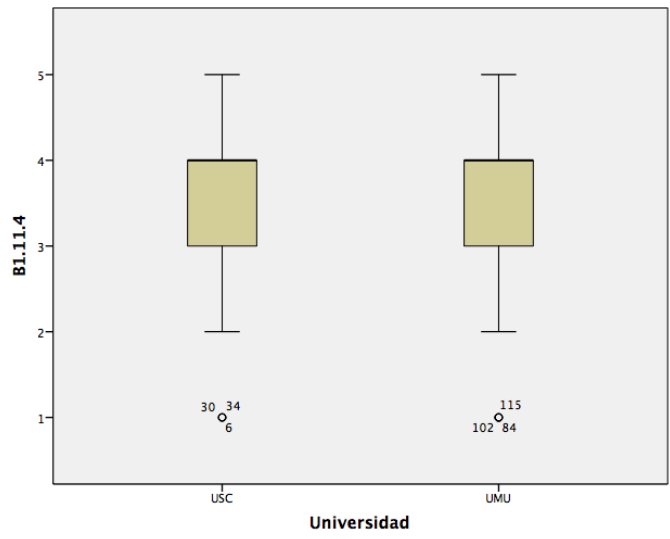

Fuente: Elaboración propia

Menos unanimidad existe en los resultados de los ítems que definían el saber histórico como objetivo (ítems 1.1, 1.4 y 1.5) o subjetivo (ítem 1.3). Con una media ligeramente superior a 3, y una desviación estándar superior a un punto, las puntuaciones son heterogéneas. Sorprende que los futuros docentes puntúen muy bajo al ítem que subraya la necesidad de introducir en los currículos educativos los orígenes de la nación $(2,66)$, mientras que le dan una puntuación significativamente mayor $(3,65)$ al ítem que afirma que la esencia de nuestra identidad hay que buscarla en los hechos del pasado. Una contradicción que podría explicarse por la tensión entre las concepciones que el alumnado tiene interiorizadas del saber histórico, consecuencia de su praxis escolar, y la formación que están recibiendo que les exige superar modelos tradicionales.

En el apartado 1.11, en el que se pide a los futuros docentes que valoren el sentido de la historia, el ítem con una puntuación media mayor es el que afirma que en la evolución histórica los hechos tienden a repetirse, con puntuaciones muy homogéneas en ambas universidades (gráfico 2). Esta visión cíclica de la historia ha sido superada hace tiempo por la historiografía. En las interpretaciones historiográficas actuales nada hace suponer que los hechos históricos han sido de alguna forma preconcebidos o siguen un sentido prediseñado. Sin embargo, esta visión de la historia que concuerda con las actuales interpretaciones historiográficas recibe por parte del alumnado una puntuación baja $(2,74)$.

Estos resultados están cierta medida conectados con el apartado 1.13, en el que se les pide que valoren los temas que creen más relevantes para la enseñanza 
de la historia. Los ítems con menos puntuación se refieren a la vida cotidiana de gente corriente; líderes políticos y militares; e historia de personajes interesantes: inventores, aventureros etc. En algunos de estos ítems hay diferencias entre universidades (gráfico 3). Sin embargo, han puntuado más alto y de forma homogénea cuestiones relacionadas con la historia estructural o la enseñanza de la historia desde una perspectiva de educación cívica.

GRÁFICO 3. RESULTADOS DESAGREGADOS POR UNIVERSIDADES DEL ÍTEM 1.13.1 "VIDA COTIDIANA DE LA GENTE CORRIENTE"

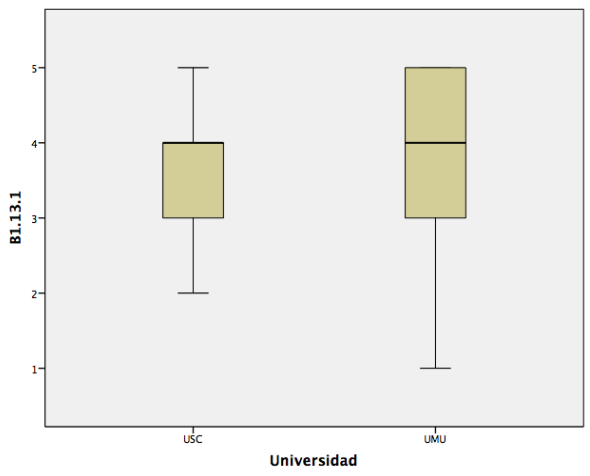

Fuente: Elaboración propia

GRÁFICO 4. RESULTADOS DESAGREGADOS POR UNIVERSIDADES DEL ÍTEM 1.13.10: GRANDES PROCESOS HISTÓRICOS DE LA HUMANIDAD (REVOLUCIÓN NEOLÍTICA, REVOLUCIÓN INDUSTRIAL)

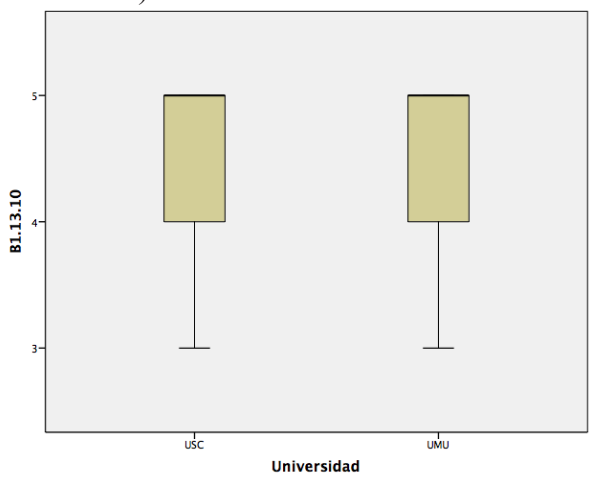

Fuente: Elaboración propia 
Las mayores puntuaciones las han recibido cuestiones como lo grandes procesos de la humanidad (ítem 1.13.10 y gráfico 4); el desarrollo del comercio, la agricultura y la industria (ítem 1.13.7); o el desarrollo de los derechos humanos, las reivindicaciones sociales y las luchas por la igualdad (ítem 1.13.12). Esta preferencia por lo estructural frente a la historia más micro tiene su correlación con los currículos y los libros de texto. En España se sigue combinando una perspectiva que parte del positivismo clásico, pero que recoge aportaciones de las primeras generaciones de la escuela de Annales. Una visión muy diferente al Reino Unido, cuyos libros de texto han sido más receptivos a la historia social y cultural, en la historia desde abajo, perspectivas de género, el conflicto o la microhistoria (Gómez y Chapman, 2017).

\section{Bloque 2: Competencias históricas y metodología docente}

TABLA 2: COMPETENCIAS HISTÓRICAS Y METODOLOGÍA DOCENTE. DATOS ESTADÍSTICOS (MEDIAS Y DESVIACIÓN ESTÁNDAR)

\begin{tabular}{|c|r|r|r|r|r|}
\hline Ítem & N & Mín. & Máx. & Media & $\begin{array}{c}\text { Desv. } \\
\text { estándar }\end{array}$ \\
\hline $\begin{array}{l}\text { 2.1. El profesor o profesora utilizaba principalmente el método } \\
\text { expositivo (lección magistral) para enseñar Historia }\end{array}$ & 155 & 3 & 5 & 4,65 &, 588 \\
\hline $\begin{array}{l}\text { 2.2. Mi principal papel como alumno/a era recoger apuntes y } \\
\text { escuchar la lección }\end{array}$ & 155 & 2 & 5 & 4,63 &, 656 \\
\hline $\begin{array}{c}\text { 2.3. El profesor o profesora utilizaba con frecuencia los debates } \\
\text { para profundizar en los contenidos históricos }\end{array}$ & 155 & 1 & 5 & 2,19 & 1,207 \\
\hline $\begin{array}{c}\text { 2.4. El profesor o profesora utilizaba estudios de caso, proyectos } \\
\text { u otros métodos de indagación como el Aprendizaje Basado } \\
\text { en Problemas }\end{array}$ & 155 & 1 & 5 & 1,72 & 1,023 \\
\hline $\begin{array}{c}\text { 2.5. El profesor o profesora utilizaba juegos de simulación, de } \\
\text { empatía o perspectiva histórica para la enseñanza de los } \\
\text { contenidos de historia }\end{array}$ & 154 & 1 & 5 & 1,64 & 1,002 \\
\hline $\begin{array}{c}\text { 2.6. El principal recurso utilizado en la clase de Historia era el } \\
\text { libro de texto }\end{array}$ & 155 & 1 & 5 & 4,54 &, 914 \\
\hline $\begin{array}{c}\text { 2.7. El profesor o profesora utilizaba con frecuencia fuentes } \\
\text { históricas primarias (documentos de la época, objetos, } \\
\text { reproducciones de artefactos, etc.) }\end{array}$ & 155 & 1 & 5 & 2,26 & 1,183 \\
\hline $\begin{array}{c}\text { 2.8. El profesor o profesora utilizaba documentales, cine o vídeos } \\
\text { seleccionados de apoyo para la enseñanza de contenidos } \\
\text { históricos }\end{array}$ & 155 & 1 & 5 & 2,91 & 1,170 \\
\hline $\begin{array}{c}\text { 2.9. Para mantener la atención y amenizar la clase el profesor o } \\
\text { profesora recurría frecuentemente a relatos y anécdotas }\end{array}$ & 155 & 1 & 5 & 2,85 & 1,258 \\
\hline $\begin{array}{c}\text { 2.10. El docente utilizaba habitualmente las TIC para profundizar } \\
\text { en los temas históricos o poder recrear situaciones del pasado }\end{array}$ & 155 & 1 & 5 & 2,01 & 1,122 \\
\hline $\begin{array}{c}\text { 2.11. Se utilizaba con frecuencia el patrimonio local o regional } \\
\text { para complementar o profundizar en los contenidos históricos }\end{array}$ & 155 & 1 & 5 & 2,34 & 1,198 \\
\hline $\begin{array}{c}\text { 2.12. El profesor o profesora utilizaba leyendas, música, } \\
\text { costumbres u otros elementos del patrimonio cultural para } \\
\text { reforzar el aprendizaje }\end{array}$ & 154 & 1 & 5 & 1,01 \\
\hline
\end{tabular}




\begin{tabular}{|c|c|c|c|c|c|}
\hline $\begin{array}{l}\text { 2.13. En el aula utilizábamos habitualmente la prensa y otros } \\
\text { medios de comunicación para contextualizar o profundizar en } \\
\text { temáticas históricas }\end{array}$ & 155 & 1 & 5 & 1,71 & ,967 \\
\hline $\begin{array}{l}\text { 2.14. El profesor utilizaba el examen como principal instrumento } \\
\text { de evaluación }\end{array}$ & 155 & 1 & 5 & 4,80 &, 527 \\
\hline $\begin{array}{l}\text { 2.15. Para superar los exámenes de historia lo que principalmente } \\
\text { utilizaba era la memorización de contenidos }\end{array}$ & 155 & 1 & 5 & 4,73 & ,658 \\
\hline 2.16.1. Explicación del profesor con apoyo del libro de texto & 155 & 1 & 5 & 2,75 & 1,107 \\
\hline $\begin{array}{l}\text { 2.16.2. Estrategias de empatía, simulación o juego de roles, o } \\
\text { perspectiva histórica }\end{array}$ & 155 & 1 & 5 & 4,26 & ,968 \\
\hline $\begin{array}{l}\text { 2.16.3. Utilizar temas clave de actualidad para conectar pasado } \\
\text { y presente }\end{array}$ & 155 & 1 & 5 & 4,50 & ,793 \\
\hline $\begin{array}{l}\text { 2.16.4. Estudios en profundidad de casos históricos concretos, } \\
\text { en los que el alumnado deba investigar a través de fuentes } \\
\text { primarias y después exponer los resultados }\end{array}$ & 155 & 1 & 5 & 4,14 & ,947 \\
\hline 2.16.5. Salidas a museos o lugares de interés histórico & 155 & 1 & 5 & 4,10 & ,913 \\
\hline 2.16.6. Debates en el aula, dirigidos, sobre temas históricos & 155 & 1 & 5 & 4,20 & ,878 \\
\hline $\begin{array}{l}\text { 2.16.7. Proyectos interdisciplinares o de Aprendizaje-Servicio } \\
\text { que conecten la historia con otras materias educativas y con } \\
\text { el entorno local }\end{array}$ & 155 & 1 & 5 & 4,17 & 1,020 \\
\hline 2.17.1. Libro de texto & 155 & 1 & 5 & 2,59 & 1,074 \\
\hline 2.17.2. Páginas web de contenido histórico & 155 & 1 & 5 & 3,25 & 914 \\
\hline 2.17.3. Fuentes documentales primarias & 155 & 2 & 5 & 4,21 & ,730 \\
\hline $\begin{array}{l}\text { 2.17.4. Fuentes orales (entrevistas a abuelos, familiares, } \\
\text { vecinos...). }\end{array}$ & 155 & 1 & 5 & 4,32 & ,779 \\
\hline 2.17.5. Prensa impresa o digital & 154 & 1 & 5 & 3,64 & ,969 \\
\hline 2.17.6. Apuntes del profesor & 154 & 1 & 5 & 3,07 & ,978 \\
\hline 2.17.7. Museos y otros lugares de interpretación patrimonial & 155 & 1 & 5 & 4,27 & 840 \\
\hline 2.17.8. Cine y documentales de temática histórica & 155 & 2 & 5 & 4,15 & ,754 \\
\hline 2.17.9. Novela histórica, cómic y literatura infantil & 154 & 1 & 5 & 3,90 & ,962 \\
\hline $\begin{array}{l}\text { 2.17.10. Reportajes en revistas de divulgación sobre temas } \\
\text { históricos }\end{array}$ & 154 & 1 & 5 & 3,85 & ,934 \\
\hline 2.17.11. Videojuegos & 155 & 1 & 5 & 3,12 & 1,130 \\
\hline B2.17.12. Fiestas y tradiciones locales de contenido histórico & 155 & 1 & 5 & 3,85 & ,917 \\
\hline 2.17.13. Patrimonio local y regional próximo & 155 & 1 & 5 & 4,16 & ,856 \\
\hline $\begin{array}{l}\text { 2.17.14. Recreaciones virtuales de museos y otros centros de } \\
\text { interés patrimonial }\end{array}$ & 155 & 1 & 5 & 3,81 & ,999 \\
\hline $\begin{array}{l}\text { 2.17.15. Aplicaciones para teléfono móvil y tabletas con } \\
\text { contenidos histórico y patrimonial }\end{array}$ & 154 & 1 & 5 & 3,62 & 1,043 \\
\hline $\begin{array}{l}\text { 2.18.1. Ejercicios que exijan la interpretación de textos e } \\
\text { imágenes de contenido histórico }\end{array}$ & 155 & 1 & 5 & 3,90 & ,862 \\
\hline $\begin{array}{l}\text { 2.18.2. Preguntas cortas sobre acontecimientos o personajes } \\
\text { históricos }\end{array}$ & 155 & 1 & 5 & 3,05 & ,963 \\
\hline $\begin{array}{l}\text { 2.18.3. Ensayos y preguntas de desarrollo sobre procesos } \\
\text { históricos }\end{array}$ & 155 & 1 & 5 & 3,16 & ,970 \\
\hline $\begin{array}{l}\text { 2.18.4. Trabajo de campo (recogida de información, realización } \\
\text { de ejercicios) a lo largo de una visita a un museo u otro lugar } \\
\text { de interés histórico }\end{array}$ & 153 & 1 & 5 & 4,35 & ,799 \\
\hline
\end{tabular}




(Conclusión)
\begin{tabular}{|l|r|r|r|r|r|}
\hline $\begin{array}{l}\text { 2.18.5. Ejercicios de empatía, simulación o perspectiva histórica } \\
\text { 2.18.6. Investigaciones de historia local }\end{array}$ & 155 & 1 & 5 & 4,29 &, 845 \\
\hline $\begin{array}{l}\text { 2.18.7. Preguntas que busquen la explicación histórica y el } \\
\text { razonamiento causal }\end{array}$ & 154 & 1 & 5 & 4,19 &, 831 \\
\hline $\begin{array}{l}\text { 2.18.8. Pruebas objetivas (tipo test, enlazar fechas con } \\
\text { acontecimientos...). }\end{array}$ & 155 & 1 & 5 & 2,80 & 1,130 \\
\hline
\end{tabular}

Fuente: Elaboración propia

En el segundo bloque se recogen percepciones sobre competencias históricas y metodología docente. En la primera parte, los recuerdos que tienen de la metodología utilizada por sus profesores de historia son bastante homogéneos (Gráfico 5). El alumnado recuerda principalmente metodologías tradicionales: lección magistral, recoger apuntes, uso del libro de texto, y el examen memorístico como principal instrumento de evaluación. Estos ítems superan el 4,5 de valoración media, con una desviación estándar muy baja. Al contrario, en mucha menor medida métodos, recuerda estrategias y recursos más relacionados con la innovación: debates, uso del patrimonio local o regional, métodos activos de aprendizaje o el uso de las TIC. Unas respuestas muy homogéneas entre universidades (Gráfico 6: ítem sobre uso del de patrimonio) que parece contradecir el prejuicio de que en las comunidades autónomas con una segunda lengua oficial se centren sólo en contenidos de su región.

GRÁFICO 5. RESULTADOS DESAGREGADOS POR UNIVERSIDADES DEL ÍTEM 2.1: EL PROFESOR O PROFESORA UTILIZABA PRINCIPALMENTE EL MÉTODO EXPOSITIVO (LECCIÓN MAGISTRAL) PARA ENSEÑAR HISTORIA

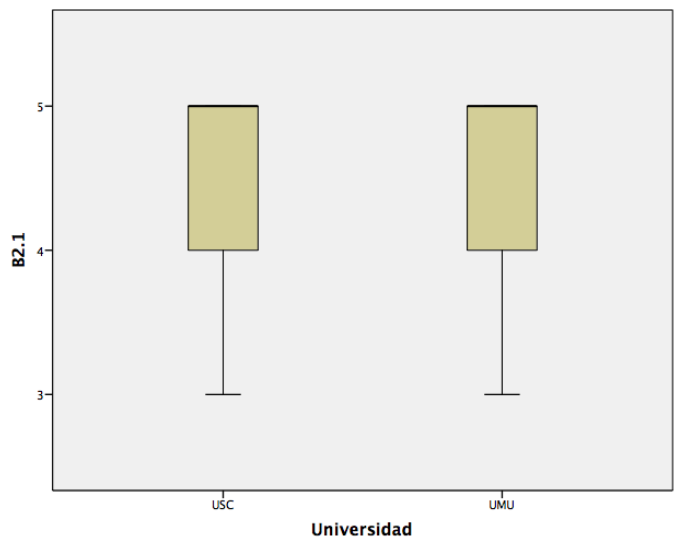

Fuente: Elaboración propia 
GRÁFICO 6. RESULTADOS DESAGREGADOS POR UNIVERSIDADES DEL ÍTEM 2.11: SE UTILIZABA CON FRECUENCIA EL PATRIMONIO LOCAL O REGIONAL PARA COMPLEMENTAR O PROFUNDIZAR EN LOS CONTENIDOS HISTÓRICOS

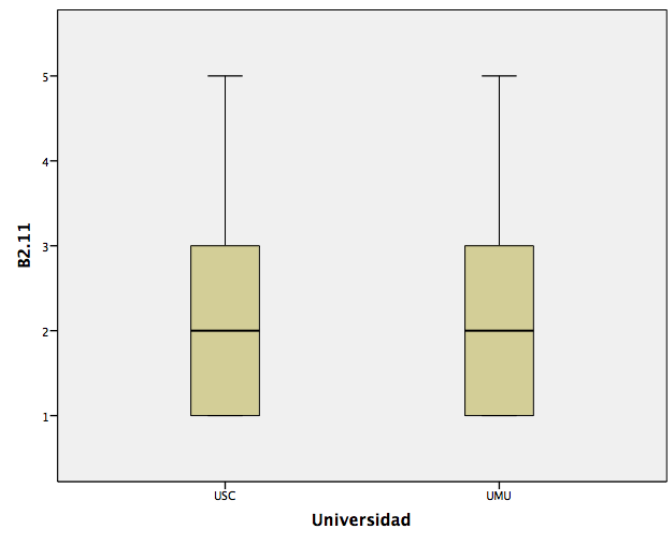

Fuente: Elaboración propia

En la segunda parte se recogen las opiniones sobre la metodología que creen más adecuada para utilizar en el aula y los resultados son opuestos. Las puntuaciones medias más altas las otorgan al uso de temas de actualidad para conectar pasado y presente $(4,50)$; el uso de recursos como fuentes primarias documentales y orales, museos, cine histórico y patrimonio local y regional (todas con puntuaciones medias superiores a 4,10); y valoran de forma muy alta (con puntuaciones medias superiores a 4,20 ) los ejercicios para evaluar las competencias históricas como trabajo de campo en museos y otros centros de interés histórico; ejercicios de empatía y perspectiva histórica; investigaciones de historia local; y preguntas de razonamiento causal. 
GRÁFICO 7. RESULTADOS DESAGREGADOS POR UNIVERSIDADES DEL ÍTEM 2.17.13: PATRIMONIO LOCAL O REGIONAL PRÓXIMO

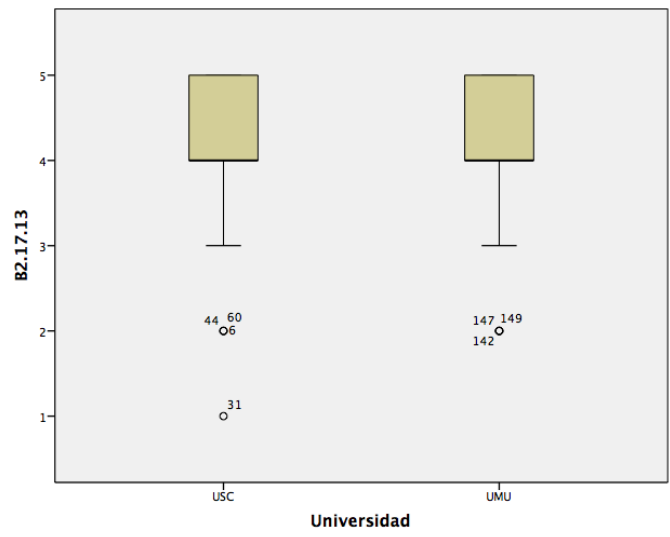

Fuente: Elaboración propia

GRÁFICO 8. RESULTADOS DESAGREGADOS POR UNIVERSIDADES DEL ÍTEM 2.17.15: APLICACIONES PARA TELÉFONO MÓVIL Y TABLETAS CON CONTENIDOS HISTÓRICO Y PATRIMONIAL

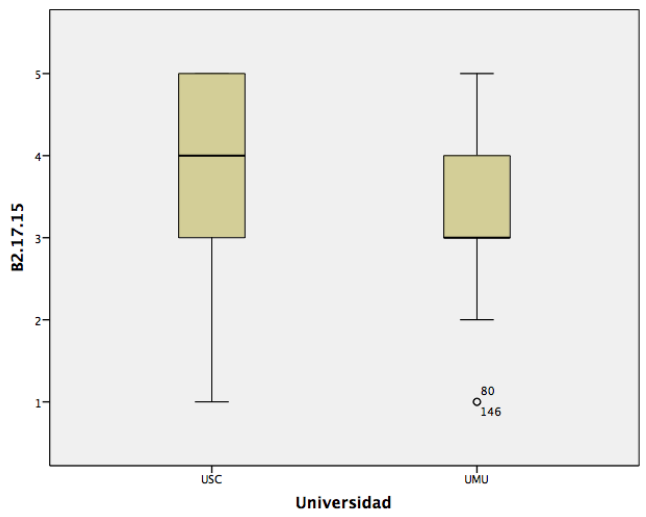

Fuente: Elaboración propia

Los datos desagregados muestran puntuaciones homogéneas (gráfico 7). Los métodos y recursos considerados a priori como más tradicionales (explicación del profesor; apuntes; libros de texto; preguntas cortas y pruebas objetivas) reciben una puntuación media muy baja, por debajo de 3 . Unas puntuaciones intermedias reciben los relacionados con las TIC: páginas web de contenido histórico; recreaciones virtuales de museos y otros centros de interés histórico 
o patrimonial; y Apps de contenido histórico y patrimonial, con puntuaciones medias entre el 3 y el 4 . Aunque hay algunas diferencias entre universidades. En la USC valoran mejor el recurso a las Apps de tipo patrimonial que los de la UMU (Gráfico 8).

\section{Bloque 3: Educación histórica y problemas sociales para la construcción de identidades}

\section{TABLA 3: EDUCACIÓN HISTÓRICA Y PROBLEMAS SOCIALES. DATOS ESTADÍSTICOS (MEDIAS Y DESVIACIÓN ESTÁNDAR)}

\begin{tabular}{|c|c|c|c|c|c|}
\hline Ítem & $\mathrm{N}$ & Mín. & Máx. & Media & $\begin{array}{l}\text { Desv. } \\
\text { estándar }\end{array}$ \\
\hline $\begin{array}{l}\text { 3.1.1. Interés por comprender algún problema social o conflicto } \\
\text { en mi entorno }\end{array}$ & 155 & 1 & 5 & 3,81 & 1,043 \\
\hline 3.1.2. Interés por entender conflictos de otros lugares. & 155 & 1 & 5 & 3,74 & ,966 \\
\hline 3.1.3. Interés por rescatar problemas sociales olvidados & 155 & 1 & 5 & 3,34 & 1,169 \\
\hline $\begin{array}{l}\text { 3.1.4. Interés por explicar elementos de la memoria de la } \\
\text { dictadura franquista }\end{array}$ & 155 & 1 & 5 & 3,19 & 1,201 \\
\hline $\begin{array}{l}\text { 3.1.5. Reivindicar la memoria de los perdedores, los oprimidos } \\
\text { y los vencidos }\end{array}$ & 154 & 1 & 5 & 3,34 & 1,233 \\
\hline 3.1.6. Interés por la construcción de identidades compartidas & 155 & 1 & 5 & 3,26 & 1,070 \\
\hline $\begin{array}{l}\text { 3.1.7. Interés por comprender a otras personas y colectivos } \\
\text { diferentes }\end{array}$ & 155 & 1 & 5 & 4,08 &, 950 \\
\hline $\begin{array}{l}\text { 3.1.8. Deseo de contribuir a solucionar problemas que nos } \\
\text { afectan }\end{array}$ & 155 & 1 & 5 & 4,13 & ,951 \\
\hline $\begin{array}{l}\text { 3.1.9. Deseo de evitar que se vuelvan a reproducir conflictos } \\
\text { similares a los del pasado }\end{array}$ & 153 & 1 & 5 & 4,27 & ,868 \\
\hline $\begin{array}{l}\text { 3.1.10. Interés por contribuir a preservar de la memoria de mi } \\
\text { comunidad }\end{array}$ & 155 & 1 & 5 & 3,54 & 1,107 \\
\hline 3.2.1. Guerra civil, represión franquista, dictadura & 155 & 1 & 5 & 4,19 & ,889 \\
\hline $\begin{array}{l}\text { 3.2.2. Conflictos sociales actuales (medioambientales, religiosos, } \\
\text { migratorios) }\end{array}$ & 155 & 2 & 5 & 4,43 &, 773 \\
\hline $\begin{array}{l}\text { 3.2.3. Preservación de patrimonios incómodos (no compartidos } \\
\text { por toda la sociedad) }\end{array}$ & 155 & 1 & 5 & 3,87 & 1,011 \\
\hline $\begin{array}{l}\text { 3.3.1. El docente debe eludir temas socialmente conflictivos en } \\
\text { el aula porque debe ser neutral y no influir en sus alumnos: } \\
\text { estos temas corresponden a las familias }\end{array}$ & 155 & 1 & 5 & 2,36 & 1,353 \\
\hline $\begin{array}{l}\text { 3.3.2. El docente debe implicarse al tratar temas socialmente } \\
\text { conflictivos en el aula y promover la posición que considera } \\
\text { éticamente correcta }\end{array}$ & 155 & 1 & 5 & 2,68 & 1,299 \\
\hline $\begin{array}{l}\text { 3.3.3. El docente debe tratar temas socialmente conflictivos en el } \\
\text { aula y propiciar el debate entre estudiantes sin expresar sus } \\
\text { propias opiniones }\end{array}$ & 155 & 1 & 5 & 3,88 & 1,219 \\
\hline $\begin{array}{l}\text { 3.3.4. El docente debe proponer en el aula el debate entre } \\
\text { diferentes perspectivas sobre temas socialmente } \\
\text { conflictivos y manifestar, no imponer, su punto de vista } \\
\text { como otro cualquiera }\end{array}$ & 155 & 1 & 5 & 4,11 & 1,079 \\
\hline
\end{tabular}


(Conclusión)

\begin{tabular}{|c|c|c|c|c|c|}
\hline $\begin{array}{l}\text { 3.4.1. Las y los profesores están preparados para tratar en el aula } \\
\text { estos temas }\end{array}$ & 155 & 1 & 5 & 3,23 & 1,084 \\
\hline $\begin{array}{l}\text { 3.4.2. Se ocupan en clase de Historia temas socialmente } \\
\text { conflictivos }\end{array}$ & 154 & 1 & 5 & 3,03 & 1,149 \\
\hline $\begin{array}{l}\text { 3.5.1. Temas socialmente conflictivos del pasado (guerra civil, } \\
\text { represión franquista, dictadura) }\end{array}$ & 155 & 1 & 5 & 3,66 & 963 \\
\hline $\begin{array}{l}\text { 3.5.2. Temas socialmente conflictivos actuales } \\
\text { (medioambientales, religiosos, migratorios) }\end{array}$ & 155 & 1 & 5 & 3,19 & 1,056 \\
\hline $\begin{array}{l}\text { 3.5.3. Preservación de patrimonios incómodos (no compartidos } \\
\text { por toda la sociedad) }\end{array}$ & 155 & 1 & 5 & 2,50 & 1,053 \\
\hline $\begin{array}{l}\text { 3.6.1. Temas socialmente conflictivos del pasado (guerra civil, } \\
\text { represión franquista, dictadura) }\end{array}$ & 155 & 1 & 5 & 4,12 &, 781 \\
\hline $\begin{array}{l}\text { 3.6.2. Temas socialmente conflictivos actuales } \\
\text { (medioambientales, religiosos, migratorios) }\end{array}$ & 155 & 2 & 5 & 4,44 & ,798 \\
\hline $\begin{array}{l}\text { 3.6.3. Preservación de patrimonios incómodos (no compartidos } \\
\text { por toda la sociedad) }\end{array}$ & 155 & 1 & 5 & 3,89 & 1,054 \\
\hline $\begin{array}{l}\text { 3.7.1. Identificar elementos de memoria de un pasado incómodo } \\
\text { o conflictivo }\end{array}$ & 155 & 1 & 5 & 3,68 & 1,011 \\
\hline 3.7.2. Recuperar historia oral & 155 & 1 & 5 & 3,57 & ,994 \\
\hline 3.7.3. Interpretar el paisaje & 154 & 1 & 5 & 3,34 & ,992 \\
\hline 3.7.4. Conocer cambios sociales & 155 & 3 & 5 & 4,37 & ,646 \\
\hline $\begin{array}{l}\text { 3.7.5. Contribuir a crear lazos comunitarios en la comunidad en } \\
\text { la que se vive }\end{array}$ & 155 & 1 & 5 & 4,16 &, 818 \\
\hline $\begin{array}{l}\text { 3.7.6. Identificar e interpretar patrimonio histórico-artístico y/o } \\
\text { monumental }\end{array}$ & 155 & 1 & 5 & 4,15 & ,828 \\
\hline 3.7.7. Identificar el posible valor y uso turístico del entorno & 155 & 1 & 5 & 3,57 & 1,093 \\
\hline 3.7.8. Preservar símbolos históricos & 155 & 1 & 5 & 3,57 & 1,105 \\
\hline 3.7.9. Preservar elementos naturales del paisaje & 155 & 1 & 5 & 4,05 & ,979 \\
\hline 3.8.1. Conocer el contexto sociocultural y ambiental del entorno & 155 & 3 & 5 & 4,41 & ,662 \\
\hline $\begin{array}{l}\text { 3.8.2. Identificar los elementos patrimoniales por su valor } \\
\text { simbólico para generar sentimientos de apego a lo propio }\end{array}$ & 155 & 1 & 5 & 3,85 & 1,056 \\
\hline $\begin{array}{l}\text { 3.8.3. Formar ciudadanos comprometidos y críticos con el } \\
\text { desarrollo sostenible }\end{array}$ & 155 & 2 & 5 & 4,57 & ,664 \\
\hline $\begin{array}{l}\text { 3.8.4. Valorar los elementos patrimoniales como recursos } \\
\text { turísticos que pueden mejorar la economía de la comunidad }\end{array}$ & 155 & 1 & 5 & 3,76 & 1,070 \\
\hline 3.9.1. Elementos de carácter medioambiental & 155 & 1 & 5 & 3,85 & ,866 \\
\hline $\begin{array}{l}\text { 3.9.2. Referentes arqueológicos, documentales y manifestaciones } \\
\text { artísticas. }\end{array}$ & 155 & 1 & 5 & 4,01 & ,894 \\
\hline 3.9.3. Oralidad y memoria & 154 & 1 & 5 & 3,66 & ,930 \\
\hline $\begin{array}{l}\text { 3.9.4. Elementos significativos y tradicionales que explican el } \\
\text { cambio social }\end{array}$ & 155 & 2 & 5 & 4,07 &, 748 \\
\hline $\begin{array}{l}\text { 3.9.5. Objetos e instrumentos que contribuyen a la construcción } \\
\text { del conocimiento científico (componentes tecnológicos e } \\
\text { industriales). }\end{array}$ & 155 & 2 & 5 & 3,95 &, 771 \\
\hline $\begin{array}{l}\text { 3.9.6. Consideración global e integrada de todas las } \\
\text { manifestaciones anteriores }\end{array}$ & 153 & 1 & 5 & 4,13 &, 864 \\
\hline
\end{tabular}

Fuente: Elaboración propia 
En el Bloque 3 se trata de identificar si los estudiantes identifican (y se identifican con) aspectos de la educación histórica que contribuyen a desarrollar una conciencia histórica: elementos y criterios relacionados con la construcción de identidades sociales que pueden proporcionar a los estudiantes una orientación ética para la vida (Rüsen, 2016, Schmidt, 2017). Se indaga sobre sus recuerdos como estudiantes en las etapas de escolarización obligatoria y se contrasta con sus percepciones y expectativas como futuros docentes.

Se ha preguntado (3.1), en primer lugar, por sus recuerdos y percepciones sobre si la asignatura de historia contribuyó a despertar interés por problemas sociales. Las opciones que comprendían, por una parte, problemas y conflictos próximos o de otros lugares, la dictadura franquista y la memoria de los vencidos, y la memoria de la comunidad; por otra, evitar que se vuelvan a reproducir conflictos similares, contribuir a solucionar problemas que consideran que les afectan actualmente e interés por comprender a otras personas y colectivos diferentes.

Todas las opciones obtuvieron una media superior a 3; pero de manera mayoritaria $>4$, y con menor desviación estándar $(<1)$ se inclinan por opciones que incluyen concepciones más convencionales (tradicionales) sobre historia: no repetir errores u horrores del pasado (3.1.9), comprender el presente (3.1.8) y empatía hacia colectivos y personas presentes en la sociedad actual (3.1.7). Las opciones que recuperan memorias conflictivas y traumáticas, como el franquismo (3.1.4) o el olvido de las víctimas de la dictadura obtuvieron menor respaldo (3.1.5). Los datos reflejan que sus recuerdos escolares corresponden a una enseñanza de la historia tradicional que solía (y suele) evitar los temas conflictivos. También habría que tener en cuenta un posible sesgo en las respuestas: que confundan lo que realmente les ha proporcionado la educación recibida que, en la mayoría de los casos ha sido muy tradicional, y lo que ellos consideran que debería haberles proporcionado. E, incluso, que estén condicionados por conocimientos de historia adquiridos fuera de las aulas y de su etapa de escolarización obligatoria. Con todo, muestran que sólo una minoría reconoce haber recibido alguna formación sobre pasados incómodos, o que implicaba una perspectiva ética crítica.

La actitud mayoritaria es muy favorable a incorporar temas controvertidos en la educación histórica reflejan valores medios elevados $(>4)$ : los alumnos consideran, mayoritariamente, que debe trabajarse en el aula sobre conflictos sociales actuales (ambientales, religiosos, migratorios: 3.2.2), y sobre la guerra civil, franquismo y dictadura (3.2.1); y con valores algo inferiores $(<4)$, sobre la preservación de patrimonios incómodos (3.2.3). En este caso puede que bastantes alumnos no hayan comprendido el concepto de patrimonio incómodo.

Nos han sorprendido los datos sobre las concepciones que tienen los alumnos a cerca de qué actitud debe adoptar el profesor cuando se suscitan en 
las aulas temas socialmente conflictivos (3.3); contrastan con trabajos previos sobre este tema (Kelly, 1986; Simoneaux, 2007). La opción con mayor apoyo es la que considera que el docente debe suscitar en las aulas el debate entre diferentes perspectivas sobre temas socialmente conflictivos y manifestar, no imponer, su punto de vista como otro cualquiera $(3.3 .4,>4)$. El $49 \%$ opta, mayoritariamente, por la respuesta, al que hay que sumar un $25,2 \%$ manifiestan estar algo de acuerdo con esta posición; es decir, casi el 75\% respaldan en mayor o menor medida esta posición. Una posición que se ha definido como de imparcialidad comprometida (Kelly, 1986; López-Facal y Santidrián, 2011) que está en línea con la perspectiva de una educación crítica, en las que se recurre a debates en las aulas sobre temas controvertidos o candentes para promover competencias en argumentación y alentar el pensamiento crítico del alumnado. Esta tendencia se confirma con los datos que corresponden a las otras opciones. En segundo lugar, con una media inferior a $4(3,88)$ se respalda la opción de que el docente debe tratar temas socialmente conflictivos en el aula y propiciar el debate entre estudiantes sin expresar sus propias opiniones (3.3.3); es decir, la opción de imparcialidad neutral.

En el cuestionario, intencionadamente, la primera opción que se ofrecía era la que se pedía su grado de acuerdo con el enunciado «el docente debe eludir temas socialmente conflictivos en el aula porque debe ser neutral y no influir en sus alumnos: estos temas corresponden a las familias» (3.3.1). Se proponía en primer lugar porque en exploraciones previas habíamos detectado que esta opción contaba con amplia aceptación. Se trata de la posición menos comprometida, menos crítica, pero muchos maestros en formación o en ejercicio comparten esta perspectiva, que cuenta igualmente con respaldo social. Sin embargo, sólo el 21,3\% manifestó estar algo o muy de acuerdo con ella, mientras que la mayoría (60\%) indican estar muy en desacuerdo o algo en desacuerdo. También son mayoría $(45,2 \%)$ los que están en desacuerdo (mucho o algo) en que el docente debe implicarse al tratar temas socialmente conflictivos en el aula y promover la posición que considera éticamente correcta (3.3.2), frente a un 30,3 que selecciona las respuestas contrarias (algo o muy de acuerdo). Los datos desagregados muestran diferencias que, en nuestra opinión, pueden deberse a los diferentes enfoques entre las dos universidades en los cursos precedentes: en la UMU, como se ha indicado, han cursado previamente asignaturas con contenidos en educación histórica, en los que se ha insistido en las metodologías activas, mientras que en la USC la única asignatura previa de didáctica de las ciencias sociales se ha centrado en educación geográfica, centrada en problemas sociales. 
GRÁFICO 9. RESULTADOS DESAGREGADOS POR UNIVERSIDADES DEL ÍTEM 3.3.1: EL DOCENTE DEBE ELUDIR TEMAS SOCIALMENTE CONFLICTIVOS EN EL AULA PORQUE DEBE SER NEUTRAL Y NO INFLUIR EN SUS ALUMNOS: ESTOS TEMAS CORRESPONDEN A LAS FAMILIAS

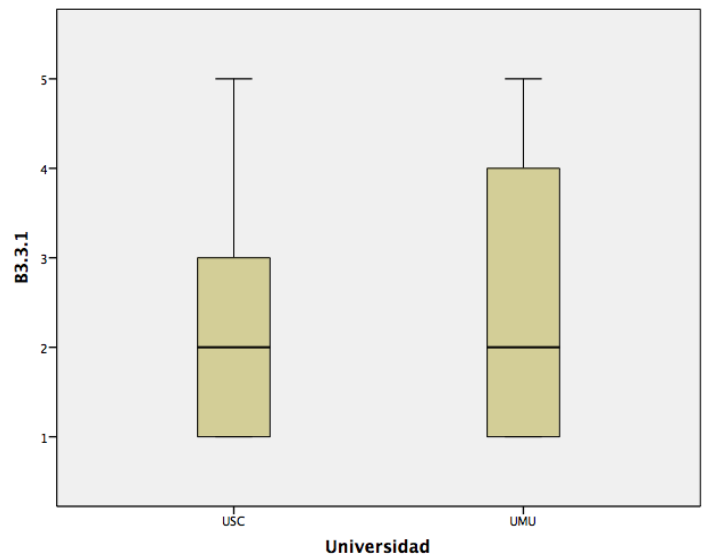

Fuente: Elaboración propia

GRÁFICO 10. RESULTADOS DESAGREGADOS POR UNIVERSIDADES DEL ÍTEM 3.3.2: EL DOCENTE DEBE IMPLICARSE AL TRATAR TEMAS SOCIALMENTE CONFLICTIVOS EN EL AULA Y PROMOVER LA POSICIÓN QUE CONSIDERA ÉTICAMENTE CORRECTA

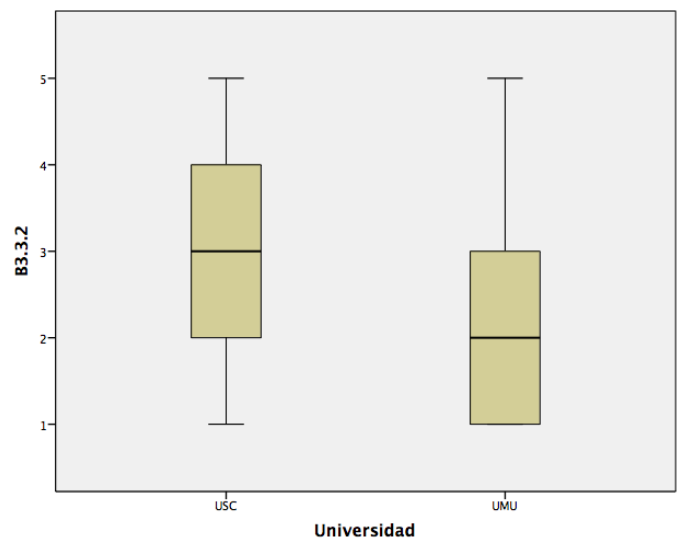

Fuente: Elaboración propia 
GRÁFICO 11. RESULTADOS DESAGREGADOS POR UNIVERSIDADES DEL ÍTEM 3.3.3: EL DOCENTE DEBE TRATAR TEMAS SOCIALMENTE CONFLICTIVOS EN EL AULA Y PROPICIAR EL DEBATE ENTRE ESTUDIANTES SIN EXPRESAR SUS PROPIAS OPINIONES

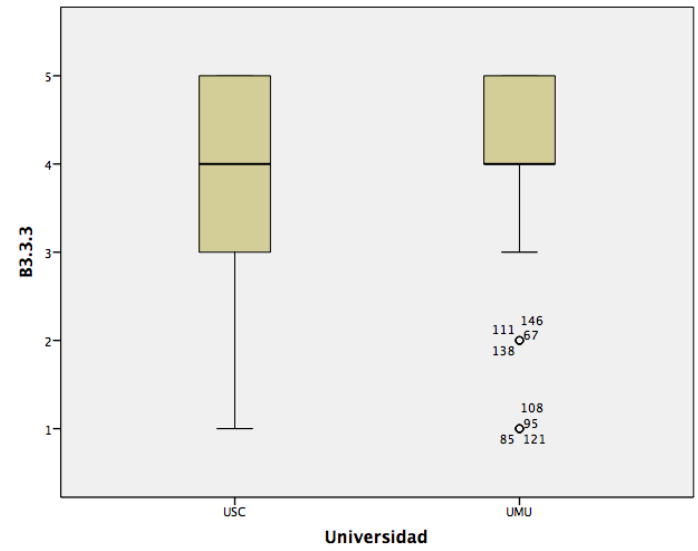

Fuente: Elaboración propia

GRÁFICO 12. RESULTADOS DESAGREGADOS POR UNIVERSIDADES DEL ÍTEM 3.3.4: EL DOCENTE DEBE PROPONER EN EL AULA EL DEBATE ENTRE DIFERENTES PERSPECTIVAS SOBRE TEMAS SOCIALMENTE CONFLICTIVOS Y MANIFESTAR, NO IMPONER, SU PUNTO DE VISTA COMO OTRO CUALQUIERA

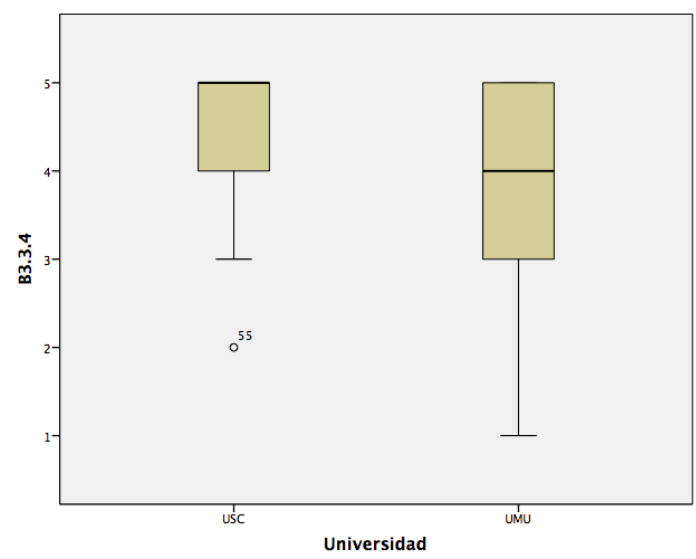

Fuente: Elaboración propia 
Con los ítems 3.4.1 y 3.4.2 se trataba de indagar sobre si creen que los profesores están preparados para abordar estos temas y si realmente lo hacen. Los resultados en ambos casos se sitúan en posiciones poco definidas, con medias ligeramente superiores a 3, aunque con bastante disparidad en las respuestas, como muestra la desviación estándar de 1,149 en el ítem 3.4.2: los docentes se ocupan de estos temas en sus aulas. Aunque en el cuestionario se les preguntaba por sus recuerdos como escolares en la etapa de educación obligatoria, posiblemente pese en las respuestas no tanto su experiencia pasada como lo que consideran o intuyen que sucede en la actualidad. Parece que tienen serias dudas de que el profesorado esté preparado para debatir temas socialmente conflictivos y, más aún, que se ocupen de ello. En los siguientes ítems (3.5) la media de los que creen que se ocupan socialmente conflictivos no es muy alta: de 3,19 sobre conflictos ambientales, religiosos o migratorios (3.5.2), algo más elevada $(3,66)$ sobre la guerra civil y la represión $(3.5 .2)$ aunque, puede que algunos asocien que en las clases de historia se haya tratado del franquismo, un contenido escolar habitual, con que se haya hecho desde un punto de vista en que se contrapongan perspectivas conflictivas sobre ello. Y es muy bajo (2,50 de media) al mencionar patrimonios incómodos (3.5.3), pero cabe la duda de si los alumnos que responden a este cuestionario entienden realmente el significado de patrimonio conflictivo. Las valoraciones son, sin embargo, muy elevadas al preguntarles por si el profesorado en activo, y ellos como docentes en el futuro, deberían ocuparse de estos temas con medias $>4$ en los dos primeros casos 3.6.1: represión franquista y 3.6.2 temas actuales conflictivos) y baja a 3,89 al preguntarles por patrimonios conflictivos.

Sobre la finalidad de tratar en las aulas temas socialmente conflictivos, las medias más elevadas corresponden a conocer cambios sociales (3.7.4), contribuir a crear lazos comunitarios (3.7.5), preservación de los paisajes (3.7.9) e identificar e interpretar el patrimonio histórico/artístico y monumental (3.7.6). Este último dato, junto con una media bastante baja para el ítem 3.7.1 (identificar elementos de memoria de un pasado incómodo y conflictivo) nos puede indicar que existe confusión sobre el significado de los problemas sociales acuciantes y, además, que coexistan concepciones bastante tradicionales sobre la educación histórica junto a manifestaciones sobre un modelo poco definido de docente crítico. La idea de que las maestras y maestros deben ser críticos parece estar asumida, pero eso no tiene por qué significar que comprendan lo que esto implica en la práctica. Al indagar sobre los objetivos de realizar una salida al entorno, las medias son muy elevadas cuando aparecen términos fácilmente reconocibles (3.8.3: Formar ciudadanos comprometidos y críticos con el desarrollo sostenible, 4,57 y muy baja desviación estándar: ,664; o, en segundo lugar, 3.8.1: Conocer el contexto sociocultural y ambiental del entorno) y baja notablemente cuando 
se relaciona con procesos de creación de identidades (3.8.2: Identificar los elementos patrimoniales por su valor simbólico para generar sentimientos de apego a lo propio: 3,85 , con una desviación estándar $>1$ ) y todavía más, cuando se relaciona el entorno como un recurso turístico (3.8.4) que, en un país con una elevada presión turística sobre el entorno, se suele percibir de manera negativa.

Por último, se indaga en torno a sus percepciones sobre las relaciones entre el patrimonio y los problemas sociales. La valoración más baja la recibe la de oralidad y memoria (3.9.2) en coherencia con otros datos. Las más elevadas (> 4), además del ítem que era previsible (3.9.4: consideración global de todas las que se enuncian) destacan las referidas al cambio social (3.9.4) y a referentes arqueológicos, monumentales y manifestaciones artísticas (3.9.2). De nuevo se detecta la contradicción, o la confusión, entre concepciones tradicionales para la enseñanza de la historia (3.9.2) que consideramos que derivan de sus experiencias educativas previas (que siguen teniendo gran influencia en el modelo docente realmente asumido) y el ideal formalmente deseable de profesor crítico que debe contribuir a desarrollar la conciencia histórica de sus estudiantes. Un modelo que probablemente sea resultado de una formación universitaria con fuerte carga teórica pero desconectada de una formación en la práctica, en aulas de primaria en las que se desarrollan experiencias coherentes con esos presupuestos.

\section{Conclusiones}

Los datos permiten identificar que la mayoría de los estudiantes de magisterio españoles asumen un modelo docente contradictorio. Existen algunas divergencias entre los estudiantes de las dos universidades objeto de estudio, pero globalmente los datos son consistentes y las diferencias pueden explicarse por disparidades en los respectivos planes de estudio y la formación recibida. Declaran asumir un modelo de profesor crítico, que debe utilizar una metodología activa y que seleccione contenidos relacionados con problemas sociales relevantes, pero no se corresponde con sus concepciones para desarrollar en la práctica una docencia coherente con este modelo. En el momento en el que se les plantea una cuestión más concreta de su práctica docente comienzan a visualizarse las contradicciones. Sus conocimientos de historia y sobre la historia reflejan concepciones muy tradicionales, resultado de su deficiente formación en educación histórica (Sáiz, Gómez y López-Facal, 2018).

La contradicción entre lo que declaran y lo que realmente asumen, puede explicarse por un modelo formativo en las universidades españolas que pone el 
énfasis en un discurso teórico mayoritario, que apuesta por un modelo profesional comprometido con el cambio social, pero desvinculado de la práctica real de las aulas, en las que siguen predominando rutinas profesionales acríticas. Unas rutinas predominantes que han sido ampliamente documentadas en el aula de historia, tanto en larga duración (Cuesta, 1998), en los recuerdos del alumnado (Martínez, Souto y Beltrán, 2006; Merchán, 2007); o en los procesos de evaluación (Gómez y Miralles, 2015). Esto puede explicar por qué los futuros maestros desvinculan un ideal de maestro que debe comprometerse con una educación que ayude a cambios sociales orientados a la consolidación y conquista de derechos, pero sus propuestas prácticas reproduzcan rutinas educativas seculares o, en el mejor de los casos, se limiten a mejorar métodos de enseñanza orientados a la consecución de estándares u objetivos formales, sin conexión con los principios éticos que deben orientar la vida de sus alumnos.

Los resultados obtenidos necesitan completarse con otros estudios más amplios. Para poder extraer datos más concluyentes es necesario ampliar la muestra del estudio y combinar con otros instrumentos de tipo cualitativo (entrevistas, grupos de discusión). No obstante, los resultados presentados apuntan a la necesidad de reformular la formación profesional de los futuros maestros con una inmersión en la práctica escolar en las aulas de primaria, en diálogo y progresión con la fundamentación teórica que les proporcione conocimientos básicos de historia y sobre historia que les permita mejorar su competencia profesional en educación histórica coherente con los principios éticos que declaran.

\section{REFERENCIAS}

Adler, S. A. (2008). The Education of Social Studies Teachers. En: Levstik, L. S. y Tyson, C. A. (Eds.). Handbook of Research on Social Studies Education (p. 329-351). New York: Routledge.

Bain, R. y Mirel, J. (2006). Setting up Camp at the Great Instructional Divide: Educating Beginning History Teachers. Journal of Teacher Education, 57 (3), 212-219.

Banks, J. A. y Parker, W. C. (1990). Social Studies Teacher Education. En: Houston, W. R. (Ed). Handbook of Research on Teacher Education (pp. 674-686). New York: Macmillan.

Bolívar, A. (2005) Conocimiento didáctico del contenido y didácticas específicas. Profesorado. Revista de currículum y formación del profesorado, 9, 2.

Cuesta, R. (1998). Clío en las aulas. La enseñanza de la Historia en España entre reformas, ilusiones y rutinas. Madrid: Akal. $260 \mathrm{pp}$. 
Darling-Hammond, L. \& Bransford, J. D. (2005). Preparing teachers for a changing world: What teachers should learn and be able to do. San Francisco, CA: Jossey-Bass.

Domínguez-Almansa, A. y López-Facal, R. (2017). Patrimonios en conflictos. Competencias cívicas y formación profesional en educación primaria. Revista de Educación, 375, 86-109.

Domínguez Castillo, J. (2015) Pensamiento histórico y evaluación de competencias. Barcelona: Graó.

Fives, H., \& Buehl, M. M. (2012). Spring cleaning for the "messy" construct of teachers' beliefs: What are they? Which have been examined? What can they tell us? In: Harris, K. R., Graham, S., Urdan, T., Graham, S., Royer, J. M. \& Zeidner, M. (Eds.). APA Handbooks in psychology. APA educational psychology handbook, Vol. 2. Individual differences and cultural and contextual factors (pp. 471-499). Washington, DC, US: American Psychological Association.

Fragnoli, K. (2005). Historical Inquiry in a Methods Classroom: Examining our Beliefs and Shedding our Old Ways. The Social Studies, 96(6), 247-255.

Gómez, C. J. y Chapman, A. (2017). Enfoques historiográficos y representaciones sociales en los libros de texto. Un estudio comparativo, España-Francia-Inglaterra. Historia y Memoria de la Educación, 6, 319-361.

Gómez, C. J., Miralles, P. y Chapman, A. (2017). Los procedimientos de evaluación en la clase de Historia. Un estudio comparativo a través de las opiniones de los docentes en formación de España e Inglaterra. Revista Electrónica Interuniversitaria de Formación del Profesorado, 20(2), 45-61.

Gómez, C. J. y Miralles, P. (2015). ¿Pensar históricamente o memorizar el pasado? La evaluación de los contenidos históricos en la educación obligatoria en España. Revista deEstudios Sociales, 52, 52-68.

Gómez, C. J., Rodríguez, R. A. y Mirete, A. B. (2018). Percepción de la enseñanza de la historia y concepciones epistemológicas. Una investigación con futuros maestros. Revista Complutense de Educación, 29(1), 237-250.

Hernández, F. \& Maquilón, J. J. (2010). Introducción a los diseños de investigación educativa. En: Nieto, S. (Ed.), Principios, métodos y técnicas esenciales para la investigación educativa (pp. 109-126). Madrid: Dykinson.

Kelly, T. (1986) Discussing controversial issues: Four perspectives on the teacher's role. Theory and Research in Social Education, 14 (113-138).

Korthagen, A. J. (2010). Situated Learning Theory and the Pedagogy of Teacher Education: Towards an Integrative View of Teacher Behavior and Teaching Learning. Teaching and Teacher Education, 26(1), 98-106.

Lévesque, S. (2014). What is the Use of the Past for Future Teachers? A Snapshot of Francophone Student Teachers in Ontario and Québec Universities. En: Sandwell, R. y 
Heyking, A. V. (Eds). Becoming a History Teacher (pp. 115-138). Toronto: University of Toronto Press.

López-Facal, R. (2014). La LOMCE y la competencia histórica. Ayer, 94, 273-285.

López-Facal, R., Miralles, P., Prats, J. y Gómez, C. J. (2017). Enseñanza de la historia y competencias educativas. Barcelona: Graó.

López-Facal, R. \& Santidrián Arias, V. (2011) Los «conflictos candentes» en el aula. Íber. Didáctica de las Ciencias Sociales, 69, 8-22.

Martínez, N., Souto, X. M. y Beltrán, J. (2006). Los profesores de historia y la enseñanza de la historia en España. Una investigación a partir de los recuerdos de los alumnos. Enseñanza de las Ciencias Sociales: Revista de Investigación, 5, 55-71.

McDiarmid, G. W. (1994). Understanding History for Teaching: A Study of the Historical Understanding of Prospective Teachers. En: Carretero, M. y Voss, J. F. (Eds.). Cognitive and Instructional Process in History and the Social Sciences (pp. 159-185). Hillsdale: Lawrence Erlbaum Associates Publishers.

Merchán, F. J. (2007). El papel de los alumnos en la clase de historia como agentes de la práctica de la enseñanza. Didáctica de las Ciencias Experimentales y Sociales, 21, 33-51.

Pollock, S. A. (2014). The Poverty and Possibility of Historical Thinking: An Overview of Recent Research into History Teacher Education. En: Sandwell, R. y Heyking, A. V. (Eds.). Becoming a History Teacher (pp. 60-74). Toronto: University of Toronto Press.

Rüsen, Jörn (2016). Contribuições para uma teoria da didática da história. Curitiba: W\&A Editores.

Sáiz, J., Gómez, C. J., y López-Facal, R. (2018). Historical thinking, causal explanation and narrative discourse in trainee teachers in Spain. Historical Encounters: A journal of historical consciousness, historical cultures, and history education, 5(1), 16-30.

Schmidt, M. A. (2017) ¿Qué hacen los historiadores cuando enseñan la Historia? Contribuciones de la teoría de Jörn Rüsen para el aprendizaje y el método de enseñanza de la Historia. Clío \& Asociados. La historia enseñada, 24, pp. 26-37.

Seixas, P. (1998). Student Teacher Thinking Historically. Theory and Research in Social Education, 26(2), 310-341.

Shulman, L.S. (1989). Paradigmas y programas de investigación en el estudio de la enseñanza: una perspectiva contemporánea. En: Wittrock, M. C. (Ed.). La investigación de la enseñanza, I. Enfoques, teorías y métodos. Barcelona: Paidós/MEC, 9-91.

Simonneaux, L. (2007): Argumentation in Socio-Scientific Contexts. In: Erduran, S. \& Jiménez-Aleixandre, M. P. Argumentation in Science Education. Springer. (179-199).

Van Sledright, B. A. y Reddy, K. (2014). Changing Epistemic Beliefs? An Exploratory Study of Cognition Among Prospective History Teacher. Tempo e Argumento, 6(11), 28-68. 
Westhoff, L. M. y Polman, J. L. (2008). Developing Preservice Teachers' Pedagogical Content Knowledge about Historical Thinking. International Journal of Social Education, 22(2), 26-38.

Wilson, S. y Wineburg, S. (1993). Wrinkles in Time and Place: Using Performance Assessment to Understand the Knowledge of History Teachers. American Educational Research Journal, 30(4), 729-769.

Woolfolk Hoy, A., Davis, H., \& Pape, S. J. (2006). Teacher knowledge and beliefs. In: Alexander, P. A. \& Winne, P. (Eds.). Handbook of educational psychology (2nd ed., pp. 715-738). Mahwah, NJ: Lawrence Erlbaum.

Texto recibido el 18 de enero de 2019. Texto aprobado el 23 de enero de 2019. 